\title{
DFT and experimental investigations of the formation and adsorption of enolic species on $\mathrm{Al}_{2} \mathrm{O}_{3}$ catalyst
}

\author{
Hongwei Gao ${ }^{\mathrm{a}, *}$, Hong $\mathrm{He}^{\mathrm{b}}$, Yunbo $\mathrm{Yu}^{\mathrm{b}}$, Tingxia Yan $^{\mathrm{c}}$ \\ a Institute of Watershed Science and Environmental Ecology, Wenzhou Medical College, Zhejiang 325035, China \\ ${ }^{\mathrm{b}}$ Research Center for Eco-Environmental Sciences, Chinese Academy of Sciences, Beijing 100085, China \\ ${ }^{\mathrm{c}}$ State Property Administration Department, Wenzhou Medical College, Zhejiang 325035, China
}

\section{A R T I C L E I N F O}

\section{Article history:}

Received 29 March 2008

Received in revised form 27 May 2008

Accepted 30 May 2008

Available online 11 June 2008

\section{Keywords:}

DFT

In situ DRIFTS

Simulated spectra

Enolic species

$\mathrm{Al}_{2} \mathrm{O}_{3}$ catalyst

\section{A B S T R A C T}

Density functional theory (DFT) calculations have been carried out to study the formation of enolic species on $\mathrm{Al}_{2} \mathrm{O}_{3}$. The formation mechanisms of surface enolic species from ethanol on $\mathrm{Al}_{2} \mathrm{O}_{3}$ have been described in detail with particular emphasis on an analysis of the geometrical structure and simulant IR spectra. The results indicate that the calculated IR spectra are in agreement with the experimental data. In addition, the adsorption energy of enolic species on $\mathrm{Al}_{2} \mathrm{O}_{3}$ catalyst surface was also investigated.

(c) 2008 Elsevier B.V. All rights reserved.

\section{Introduction}

Pioneering work of the selective catalytic reduction (SCR) of $\mathrm{NO}_{x}$ in lean burn conditions using $\mathrm{Cu} / \mathrm{ZSM}-5$ catalyst has been done by Iwamoto et al. [1] and Held et al.[2]. The selective catalytic reduction of NO by hydrocarbons (HC-SCR of NO) is a potential method to control the emissions from stationary sources and from vehicles of which the engine operates in the oxygen-rich conditions (e.g. diesel and lean-burn engine). The mechanism of HC-SCR of NO in the presence of excess oxygen over $\mathrm{Ag} / \mathrm{Al}_{2} \mathrm{O}_{3}$ has been proposed follows as [3-7]:

$$
\begin{aligned}
\mathrm{NO}+\mathrm{O}_{2}+\mathrm{C}_{2} \mathrm{H}_{5} \mathrm{OH} & \rightarrow \mathrm{NO}_{x}+\mathrm{C}_{x} \mathrm{H}_{y} \mathrm{O}_{z} \rightarrow \mathrm{R}-\mathrm{NO}_{2}+\mathrm{R}-\mathrm{ONO} \\
& \rightarrow-\mathrm{NCO}+-\mathrm{CN}+\mathrm{NO}+\mathrm{O}_{2} \rightarrow \mathrm{N}_{2}
\end{aligned}
$$

In our lab, we have studied the mechanism of SCR of NOx using $\mathrm{C}_{2} \mathrm{H}_{5} \mathrm{OH}, \mathrm{CH}_{3} \mathrm{CHO}$ or $\mathrm{C}_{3} \mathrm{H}_{6}$ as reductants on the $\mathrm{Ag} / \mathrm{Al}_{2} \mathrm{O}_{3}$ catalyst $[8,9]$. We found that $\mathrm{C}_{2} \mathrm{H}_{5} \mathrm{OH}$ has a higher efficiency than other reductants. In these experiments, we found a novel surface species (an enolic species $\mathrm{CH}_{2}=\mathrm{CH}-\mathrm{O}^{-}$). This enolic species has been suggested as an important reaction intermediate which relates to the higher efficiency for the SCR of $\mathrm{NO}_{x}$ using $\mathrm{C}_{2} \mathrm{H}_{5} \mathrm{OH}$ as a reductant [9].

In our previous studies [10,11], theoretical models have been proposed to study the adsorption of enolic species on the $\mathrm{Ag}$ $\mathrm{Al}_{2} \mathrm{O}_{3}$ and $\mathrm{Ag}-\mathrm{Pd} / \mathrm{Al}_{2} \mathrm{O}_{3}$ catalyst surface. In order to investigate

\footnotetext{
* Corresponding author. Tel./fax: +86 57786699570 .

E-mail address: gaohongw369@hotmail.com (H. Gao).
}

the interaction of enolic species with the surface of catalyst in detail, theoretical work and experiment of the NO reduction by ethanol were performed on the pure $\mathrm{Al}_{2} \mathrm{O}_{3}$. Auxiliary computer simulation of IR spectra with density functional theory (DFT) quantum mechanical methods affords highly powerful and reliable tools for analytical chemistry by means of in situ diffuse reflectance infrared Fourier transform spectroscopy (DRIFTS). However, little work with respect to the calculation of enolic species adsorption on the $\mathrm{Al}_{2} \mathrm{O}_{3}$ catalyst surface has been performed.

In this paper, we report on studies of the adsorption and reaction of enolic species over the $\mathrm{Al}_{2} \mathrm{O}_{3}$ catalyst using experimental and theoretical methods. This study aims to utilize in situ DRIFTS and stimulant ones toward the understanding of the formation of these active sites on the $\mathrm{Al}_{2} \mathrm{O}_{3}$ catalyst and their involvement in the mechanism of the SCR of NO. A fundamental understanding of the mechanism of the SCR of NO is believed to be essential for the development of a catalyst and improvement for potential application.

\section{Experimental}

The $\mathrm{Al}_{2} \mathrm{O}_{3}$ catalyst was calcined at $450{ }^{\circ} \mathrm{C}$ and $600^{\circ} \mathrm{C}$ for three hours, respectively. In situ diffuse reflectance infrared Fourier transform spectroscopy (DRIFTS) spectra were recorded with a Nexus 670 (Thermo Nicolet) FT-IR, equipped with an in situ diffuse reflection chamber and a high sensitivity MCT detector. The pure $\gamma-\mathrm{Al}_{2} \mathrm{O}_{3}$ material for the in situ DRIFTS studies was finely ground and placed into a ceramic crucible in the in situ chamber. Mass 
flow controllers and a sample temperature controller were used to simulate the real reaction conditions, such as mixture of gases, pressure and sample temperature. Prior to recording each DRIFTS spectrum, the sample was heated in situ in $10 \% \mathrm{O}_{2} / \mathrm{N}_{2}$ flow at $873 \mathrm{~K}$ for $1 \mathrm{~h}$, then cooled to the desired temperature for taking a reference spectrum. All gas mixtures were fed at a flow rate of $100 \mathrm{ml} / \mathrm{min}$. All spectra were measured with a resolution of $4 \mathrm{~cm}^{-1}$ and with an accumulation of 100 scans.

\section{Theoretical section}

All calculations were performed using the Gaussian98 program. The properties of the calculated models were determined through the application of density functional theory (DFT) using the B3P86 gradient corrected function (Becke's 3 parameter function with the non-local correlation provided by the Perdew 86 expression). The LANL2DZ effective core potential basis set was used for all of the calculations. The LANL2DZ basis replaces the $1 \mathrm{~s}$ through $2 \mathrm{p}$ electrons of the heavy atoms with a potential field for a considerable computational savings. A double- $\zeta$ quality dunning basis was used for the light atoms and the remaining heavy atom electrons. Stability calculations confirmed the ground-state configuration of all the wave functions. The calculated vibration frequencies and infrared intensity of the vibration normal modes using Gaussian98 are picked up by the GaussView 3.0 package.

\section{Results and discussion}

\subsection{Experimental spectra}

Fig. 1 shows the in situ DRIFT spectra of $\mathrm{Al}_{2} \mathrm{O}_{3}$ in a flow of $\mathrm{C}_{2} \mathrm{H}_{5} \mathrm{OH}(1565 \mathrm{ppm})+\mathrm{O}_{2}(10 \%)$ at a temperature range of $473-$ $873 \mathrm{~K}$ in steady states. Exposure of this catalyst to the feeding gas resulted in the appearance of five peaks $(1655,1583,1466$, 1392 and $1335 \mathrm{~cm}^{-1}$ ). Peaks at 1583 and $1466 \mathrm{~cm}^{-1}$ were assigned to $v_{\mathrm{as}}(\mathrm{OCO})$ and $v_{\mathrm{s}}(\mathrm{OCO})$ of acetate, respectively [12-15]. According to our earlier studies [8,9], peaks at 1655,1392 and

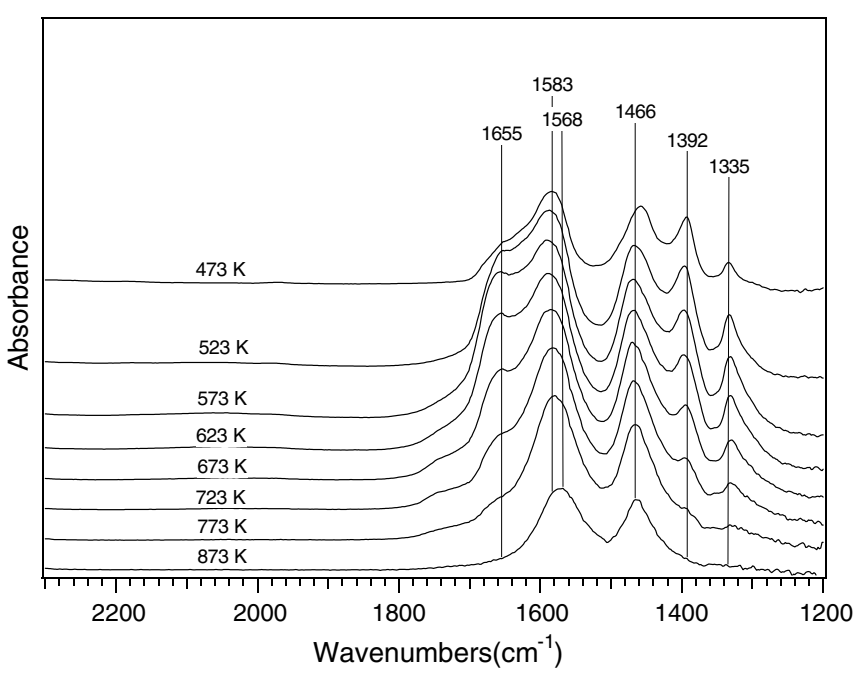

Fig. 1. The in situ DRIFTS spectra of adsorbed species in steady states on $\mathrm{Al}_{2} \mathrm{O}_{3}$ in a flow of $\mathrm{C}_{2} \mathrm{H}_{5} \mathrm{OH}+\mathrm{O}_{2}$ at $473-873 \mathrm{~K}$.

$1335 \mathrm{~cm}^{-1}$ were assigned to asymmetric stretching vibration, symmetric stretching vibration and $\mathrm{C}-\mathrm{H}$ deformation vibration modes of adsorbed enolic species, respectively. Apparently, the acetate species is predominant during the oxidation of $\mathrm{C}_{2} \mathrm{H}_{5} \mathrm{OH}$ on the $\mathrm{Al}_{2} \mathrm{O}_{3}$ surface in the all temperature region. It was worth noting that the enolic species peaks were observed within a low temperature range of $473-673 \mathrm{~K}$. Within a high temperature range of $773-873 \mathrm{~K}$, however, the peak intensity of surface enolic species becomes weak.

4.2. Mechanism for the formation of adsorbed enolic species over $\mathrm{Al}_{2} \mathrm{O}_{3}$ catalyst

On the basis of DRIFTS (Fig. 1) and TPD-MS [8,9], we proposed the mechanism for the formation of adsorbed enolic species $\left(\mathrm{CH}_{2}=\mathrm{CH}-\mathrm{CH}=\mathrm{CH}-\mathrm{O}^{-}\right)-\mathrm{M}^{+}$over $\mathrm{Al}_{2} \mathrm{O}_{3}$ catalyst as follows:
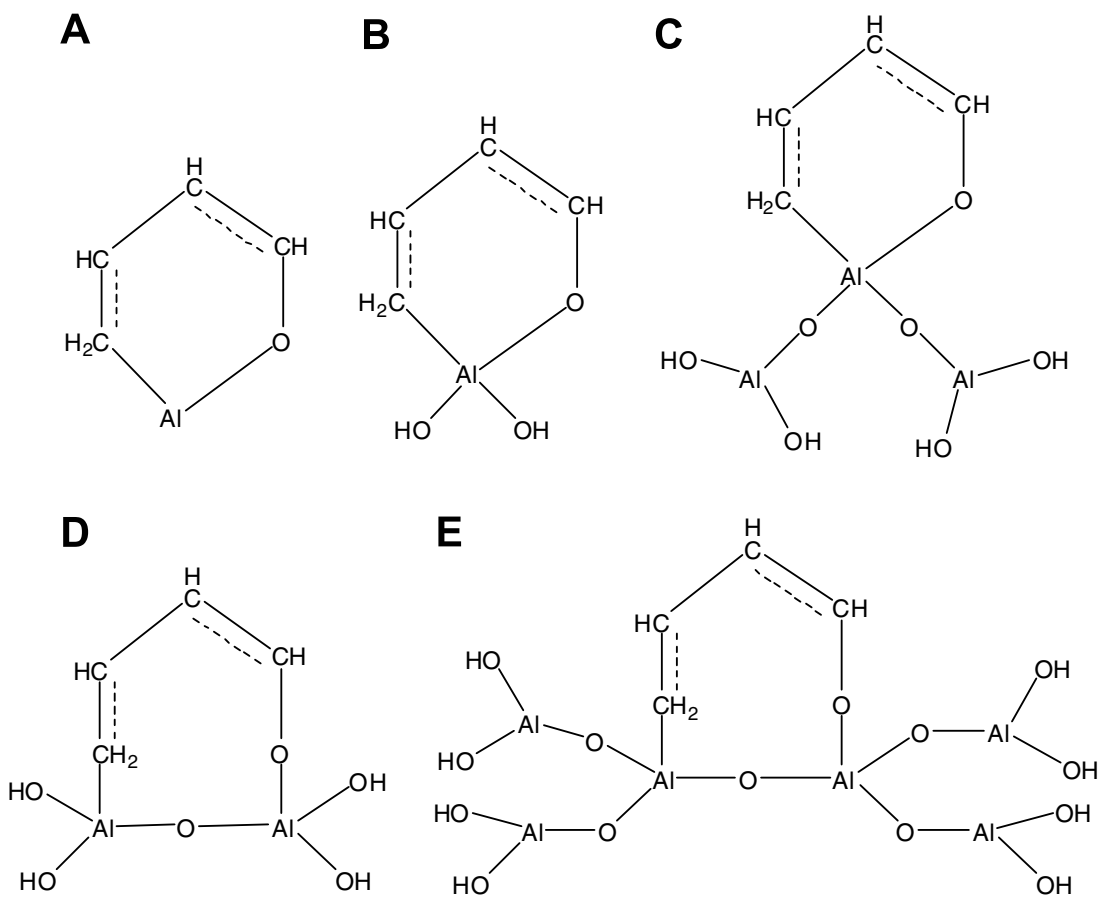

Fig. 2. The chemical structures of the computational models (A-E) for enolic species on $\mathrm{Al}_{2} \mathrm{O}_{3}$ catalyst. 
$\mathrm{C}_{2} \mathrm{H}_{5} \mathrm{OH} \stackrel{\text { oxidation }}{\underset{\mathrm{Al}_{2} \mathrm{O}_{3}}{\longrightarrow}} \mathrm{CH}_{3} \mathrm{CHO} \stackrel{\text { aldol condensation }}{\longrightarrow} \mathrm{CH}_{3} \mathrm{CH}=\mathrm{CHCHO} \stackrel{\text { isomerization }}{\longrightarrow}$<smiles>C=CC=CO</smiles>

$\mathrm{M}=\mathrm{Al}$

$\mathrm{C}_{2} \mathrm{H}_{5} \mathrm{OH}$ is first catalytically oxidized to $\mathrm{CH}_{3} \mathrm{CHO}$, which then condensate and dehydrate to yield $\mathrm{CH}_{3} \mathrm{CH}=\mathrm{CHCHO}$, followed by isomerization reaction to $\mathrm{CH}_{2}=\mathrm{CHCH}=\mathrm{CHOH}$ compound, and a further reaction of this compound finally leads to the formation of $\left(\mathrm{CH}_{2}=\mathrm{CH}-\mathrm{CH}=\mathrm{CH}-\mathrm{O}^{-}\right)-\mathrm{M}^{+}$.

\subsection{Optimized structure}

The chemical structures $\left(\mathrm{CH}_{2}=\mathrm{CH}-\mathrm{CH}=\mathrm{CH}-\mathrm{O}^{-}\right)-\mathrm{M}^{+}$of the calculation models (A-E) for the enolic species adsorption on $\mathrm{Al}_{2} \mathrm{O}_{3}$ catalyst are shown in Fig. 2. The optimized structures for the calculated models (A-E) are depicted in Fig. 3. The equilibrium internuclear distance of $\mathrm{C}=\mathrm{C}$ bond was equal to $1.38-1.42 \AA$, which is close to the experimental value of $1.40 \AA$. It was also found that the $\mathrm{C}-\mathrm{O}$ bond distance obtained here agrees well with the previously reported results [16].

\subsection{Comparison of simulated and experimental spectra}

Calculated vibration frequencies (in $\mathrm{cm}^{-1}$ ) and IR intensity (in $\mathrm{km} / \mathrm{mol}$ ) for the calculated models (A-E) at B3P86/LANL2DZ

A

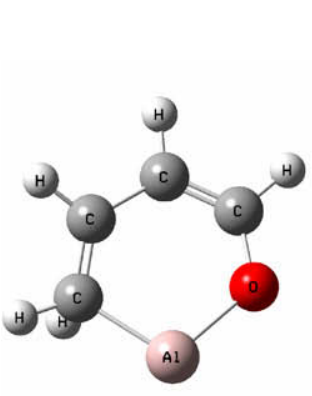

D

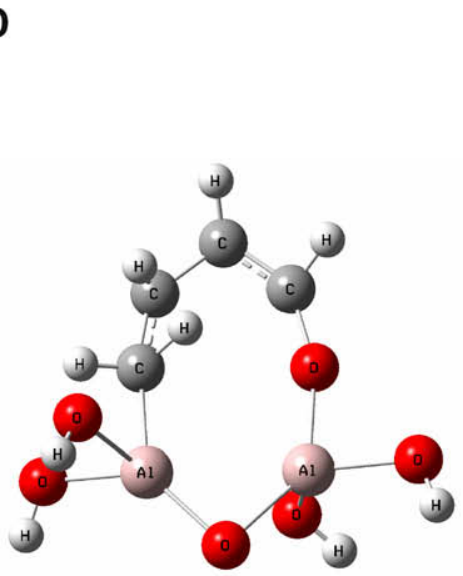

level, and corresponding frequencies in the experimental gas-phase spectra are listed in Table 1 . From the analysis of animations of normal vibration modes, it is clear that many vibrations have a high degree of mixing with other modes. Therefore, we provide in the following tentative assignments for only the intense spectral features in the vibration spectra of the molecule based on the literatures and our spectral analysis [12-22]. Simulant spectra for the models (A-E) are shown in Figs. 4 and 5.

Table 1

Calculated vibration frequencies (in $\mathrm{cm}^{-1}$ ) and IR intensity (in $\mathrm{km} / \mathrm{mol}$ ) for the calculated models (A-E) at B3P86/LANL2DZ level, and corresponding frequencies in the experimental gas-phase spectra.

\begin{tabular}{llrll}
\hline Model & $\begin{array}{l}\text { Frequency } \\
\left(\mathrm{cm}^{-1}\right)\end{array}$ & $\begin{array}{c}\text { Intensity } \\
(\mathrm{km} / \mathrm{mol})\end{array}$ & $\begin{array}{l}\text { experiment } \\
\left(\mathrm{cm}^{-1}\right)\end{array}$ & Vibration mode \\
\hline A & 1694 & 127 & 1655 & Enolic species a-str. \\
& 1361 & 86 & 1392 & Enolic species str. \\
& 1352 & 54 & 1335 & C-H def. \\
B & 1570 & 138 & 1655 & Enolic species a-str. \\
& 1406 & 57 & 1392 & Enolic species str. \\
& 1376 & 16 & 1335 & C-H def. \\
C & 1566 & 336 & 1655 & Enolic species a-str. \\
& 1438 & 15 & 1392 & Enolic species str. \\
& 1364 & 142 & 1335 & C-H def. \\
D & 1586 & 148 & 1655 & Enolic species a-str. \\
& 1463 & 69 & 1392 & Enolic species str. \\
& 1314 & 5 & 1335 & C-H def. \\
E & 1634 & 235 & 1655 & Enolic species a-str. \\
& 1406 & 120 & 1392 & Enolic species str. \\
& 1324 & 55 & 1335 & C-H def. \\
\hline
\end{tabular}

\section{C}
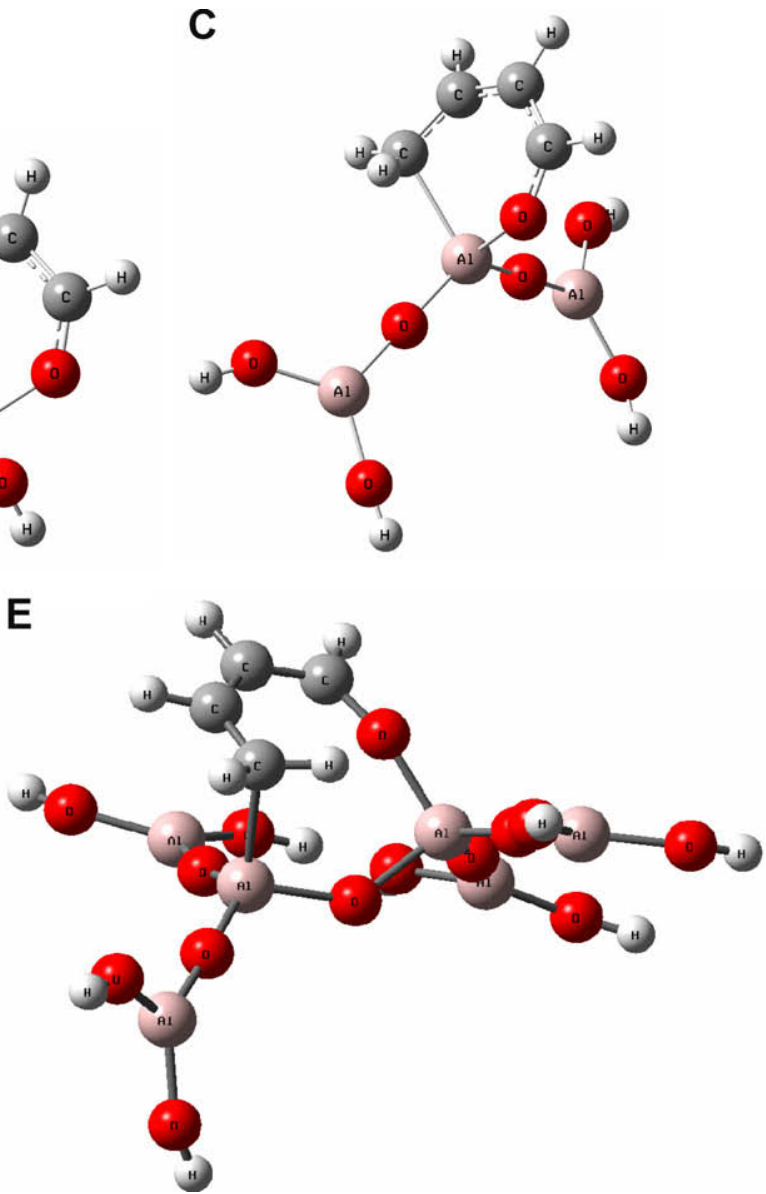

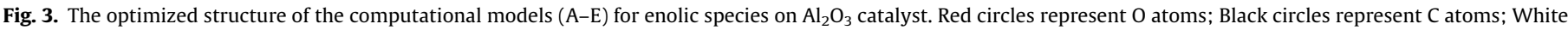
circles represent $\mathrm{H}$ atoms; Gray circles represent $\mathrm{Al}$ atoms. (For interpretation of color mentioned in this figure the reader is referred to the web version of the article.) 
A

Infrared Spectrum

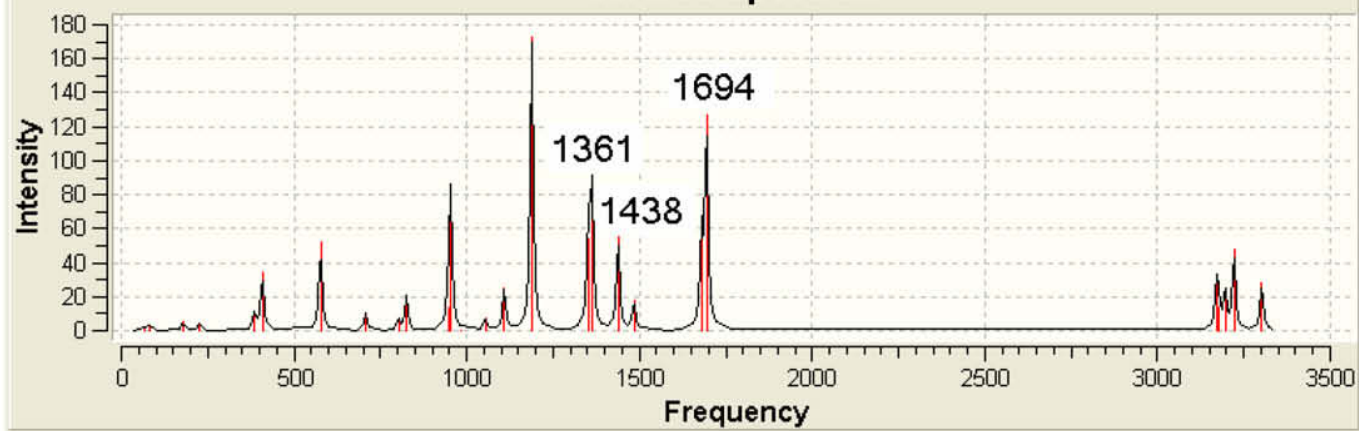

B
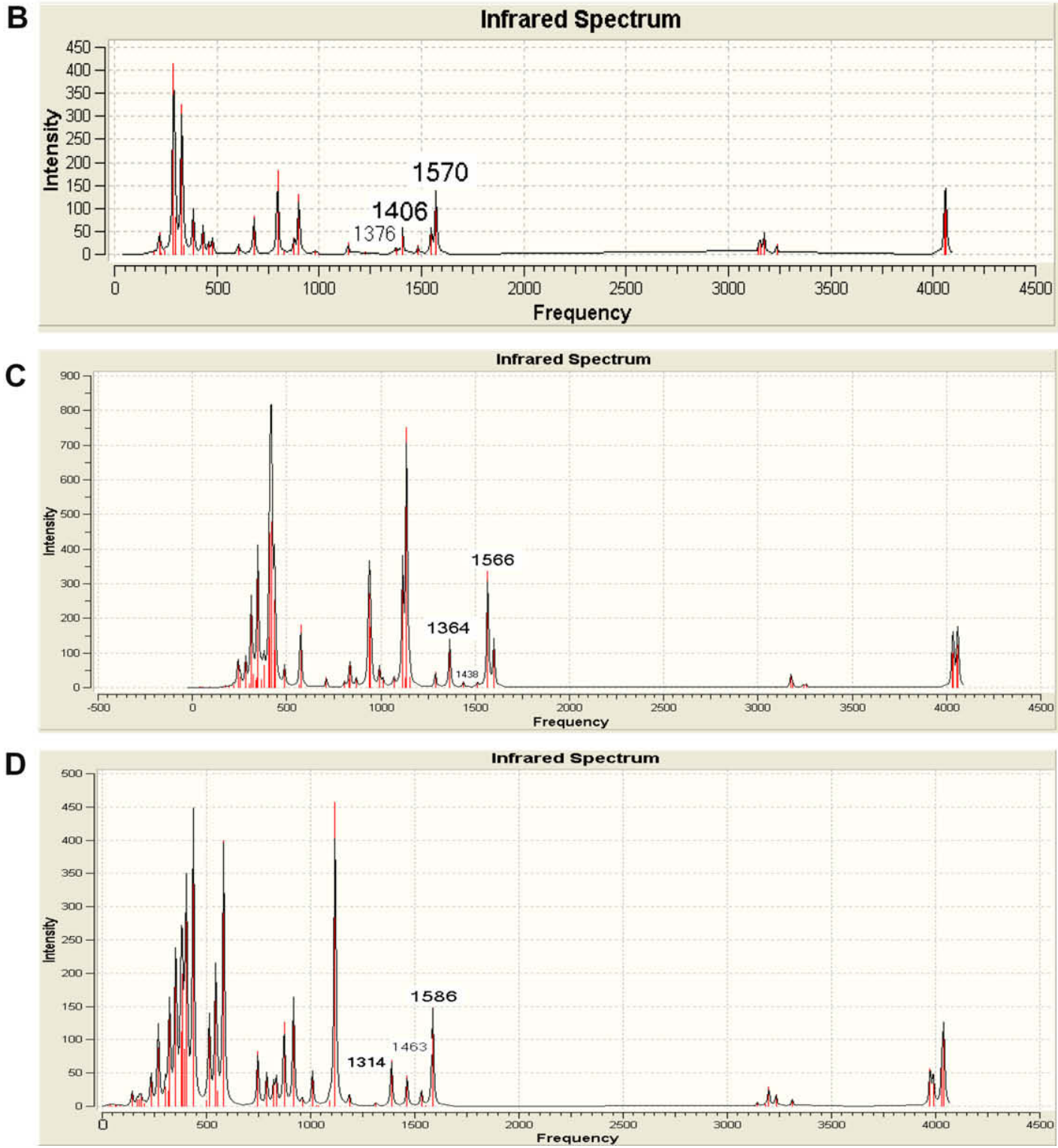

Fig. 4. Calculated vibration IR spectra for the computational models (A-D) at B3P86/LANL2DZ level.

The calculated antisymmetric stretching vibrational modes of the adsorbed enolic species for the models (A-E) are 1694, 1570, 1566, 1586 and $1634 \mathrm{~cm}^{-1}$, respectively (Figs. 4 and 5). In comparison with the same experimental frequency of $1655 \mathrm{~cm}^{-1}$, the error is on average about $39 \mathrm{~cm}^{-1}$ for model (A), $-85 \mathrm{~cm}^{-1}$ for model (B), $-89 \mathrm{~cm}^{-1}$ for model (C), $-69 \mathrm{~cm}^{-1}$ for model (D) and $-21 \mathrm{~cm}^{-1}$ for model (E). The calculated frequency of model
(E) at $1634 \mathrm{~cm}^{-1}$ with $235 \mathrm{~km} / \mathrm{mol}$ intensity is in relatively good matches of the most intense bands at $1655 \mathrm{~cm}^{-1}$ in the experimental spectrum (Fig. 1 ). The $\mathrm{C}=\mathrm{C}$ stretching mode was calculated at $1634 \mathrm{~cm}^{-1}$ with $235 \mathrm{~km} / \mathrm{mol}$ intensity in the simulant spectrum of the structure $\left(\mathrm{CH}_{2}=\mathrm{CH}-\mathrm{CH}=\mathrm{CH}-\mathrm{O}^{-}\right)-\mathrm{M}^{+}$(Fig. 4). This mode was odserved at $1655 \mathrm{~cm}^{-1}$ in the infrared spectrum of the adsorbed molecule (Fig. 1). 


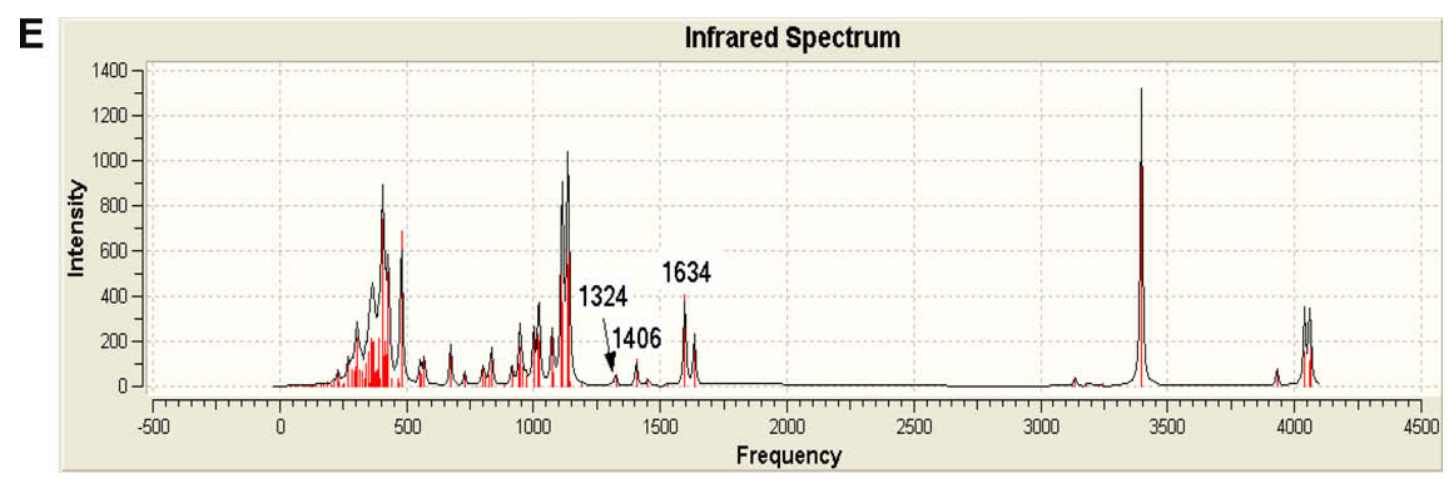

Fig. 5. Calculated vibration IR spectra for the computational model E at B3P86/LANL2DZ level.

The calculated symmetric stretching vibrational modes of the adsorbed enolic species for the models (A-E) are 1438, 1406, 1438, 1463 and $1406 \mathrm{~cm}^{-1}$, respectively (Figs. 4 and 5). For the same experimental frequency of $1392 \mathrm{~cm}^{-1}$, overestimation of experimental frequency values is about $3.30 \%$ for model (A), $1.00 \%$ for model (B), $3.30 \%$ for model (C), $5.10 \%$ for model (D) and $1.00 \%$ for model (I). The symmetric stretching vibrational mode of the adsorbed enolic species of model (B) calculated at $1406 \mathrm{~cm}^{-1}$ with $57 \mathrm{~km} / \mathrm{mol}$ intensity is only $14 \mathrm{~cm}^{-1}$ higher than the experimental spectrum at $1392 \mathrm{~cm}^{-1}$ with strong absorbance within $1.00 \%$ error. The model (E) has the same result. The expressed frequency at $1406 \mathrm{~cm}^{-1}$ for the model (A) and model (E) in Figs. 4 and 5 is in relatively good matches of the most intense bands at $1392 \mathrm{~cm}^{-1}$ in the experimental spectrum (Fig. 1).

The calculated $\mathrm{C}-\mathrm{H}$ deformation vibrational mode of the adsorbed enolic species for the models (A-E) is 1361, 1376, 1364, 1314 and $1324 \mathrm{~cm}^{-1}$, respectively (Figs. 4 and 5). In comparison with the same experimental frequency of $1335 \mathrm{~cm}^{-1}$, the error is on average about $26 \mathrm{~cm}^{-1}$ for model (A), $41 \mathrm{~cm}^{-1}$ for model (B), $29 \mathrm{~cm}^{-1}$ for model (C), $-21 \mathrm{~cm}^{-1}$ for model (D) and $-11 \mathrm{~cm}^{-1}$ for model (E). The calculated spectra of model (E) at $1324 \mathrm{~cm}^{-1}$ with $55 \mathrm{~km} / \mathrm{mol}$ intensity in Fig. 5 is in relatively good matches of the most intense bands at $1335 \mathrm{~cm}^{-1}$ in the experimental spectrum (Fig. 1).

Comparison with the experimental data shows that the spectra of model E simulated by DFT-B3P86 evidently best match the experimental counterparts for overwhelming majority of the calculated models (A-E) considered in the present study.

\subsection{Adsorption energy}

The adsorption energies ( $E_{\text {ads }}$ ) values in the present study are deduced

$E_{\text {ads }}=E_{\text {cluster/adsorbate }}-E_{\text {cluster }}-E_{\text {adsorbate }}$

where $E_{\text {cluster/adsorbate }}$ is the total energy of the adsorbate on the cluster, $E_{\text {cluster }}$ is the total energy of the bare cluster (catalyst), and $E_{\text {adsorbate }}$ is the energy of the adsorbate (enolic species).

The calculated $E_{\text {ads }}$ of models (A-E) is $-196.43,-157.88$, $-160.93,-115.47,-106.85 \mathrm{kcal} / \mathrm{mol}$, respectively. The negative $E_{\text {ads }}$ values indicate that the adsorbed state (cluster/adsorbate) is energetically favorable. The high $E_{\text {ads }}$ value means that the enolic species easily adsorbed on the surface of the $\mathrm{Al}_{2} \mathrm{O}_{3}$ catalyst. Based on the entire comparison of the $E_{\text {ads }}$ values, it is clear that the order of the energetic stability of the adsorption states of the enolic species on the $\mathrm{Al}_{2} \mathrm{O}_{3}$ catalyst surface can be described as model (A) $>$ model $($ C $)>$ model $($ B $)>$ model $($ D $)>$ model $($ E). All models have big $E_{\text {ads }}$ value, therefore, we consider that the enolic species easily formed on the $\mathrm{Al}_{2} \mathrm{O}_{3}$ catalyst surface.

\section{Conclusion}

The calculated IR spectrum for the model (E) is of reasonable similarity to the corresponding experimental spectrum. Furthermore, calculated antisymmetric and symmetric stretching vibrational modes of the adsorbed enolic species and calculated $\mathrm{C}-\mathrm{H}$ deformation vibrational mode of the adsorbed enolic species are in good agreement with experimental data. The result of the adsorption energy suggests that enolic species easily adsorbed on the $\mathrm{Al}_{2} \mathrm{O}_{3}$ catalyst surface. The calculations show clearly that simulating infrared spectra with density functional theory (DFT) quantum mechanical method can be considered as the advantageous auxiliary tool for analyzing the mechanism of the enolic species adsorption over the $\mathrm{Al}_{2} \mathrm{O}_{3}$ catalyst.

\section{Acknowledgements}

This work was financially supported by the College Science Fund for Start-up Program of Wenzhou Medical College (QTJ07014). This work was also financially supported by the Ministry of Science and Technology of China (2006AA060304).

\section{References}

[1] M. Iwamoto, H. Yahiro, S. Shundo, Y. Yu-u, N. Mizuno, Appl. Catal. 69 (1991) L15.

[2] W. Held, A. Koenig, T. Richter, L. Puppe, SAE, 1990, paper 900496.

[3] M. Misono, Y. Hirao, C. Yokoyama, Catal. Today 38 (1997) 157.

[4] J.T. Miller, E. Glusker, R. Peddi, T. Zheng, J.R. Regalbuto, Catal. Lett. 55 (1998) 15.

[5] Y. Yan, H.H. Kung, W.M.H. Sachtler, M.C. Kung, J. Catal. 175 (1998) 294

[6] C. Yokoyama, M. Misono, J. Catal. 150 (1994) 9.

[7] K.A. Bethke, C. Li, M.C. Kung, B. Yang, H.H. Kung, Catal. Lett. 31 (1995) 287.

[8] Y. Yu, H. He, Q. Feng, J. Phys. Chem. B 107 (2003) 13090.

[9] Y. Yu, H. He, Q. Feng, H. Gao, X. Yang, Appl. Catal. B 49 (2004) 159.

[10] H. Gao, H. He, Y. Yu, Q. Feng, J. Phys. Chem. B 109 (2005) 13291.

[11] H. Gao, H. He, Q. Feng, J. Wang, Spectrochimica Acta A: Mol. Biomol. Spectrosc. 61 (2005) 3117.

[12] K. Shimizu, J. Shibata, H. Yoshida, A. Satsuma, T. Hattori, Appl. Catal. B 30 (2001) 151.

[13] F.C. Meunier, V. Zuzaniuk, J.P. Breen, M. Olsson, J.R.H. Ross, Catal. Today 59 (2000) 287

[14] F.C. Meunier, J.P. Breen, V. Zuzaniuk, M. Olsson, J.R.H. Ross, J. Catal. 187 (1999) 493.

[15] K. Shimizu, A. Satsuma, T. Hattori, Appl. Catal. B 25 (2000) 239.

[16] H.G. Mack, C.O. Della Vedova, H. Wellner, J. Mol. Struct. 291 (1993) 197.

[17] Y. Koga, T. Nakanaga, K. Sugawara, A. Watanabe, M. Sugie, H. Takeo, S. Kondo, C. Matsumura, J. Mol. Spectrosc. 145 (1991) 315.

[18] D.-L. Joo, A.J. Merer, D.J. Clouthier, J. Mol. Spectrosc. 197 (1999) 68.

[19] M. Hawkins, L. Andrews, J. Am. Chem. Soc. 105 (1983) 2523.

[20] M. Rodler, C.E. Blom, A. Bauder, J. Am. Chem. Soc. 106 (1984) 4029

[21] S. Saito, Chem. Phys. Lett. 42 (1976) 399.

[22] M. Rodler, A. Bauder, J. Am. Chem. Soc. 106 (1984) 4025. 